\title{
14. SEDIMENTARY STRUCTURES OF PHILIPPINE SEA AND SEA OF JAPAN SEDIMENTS, DSDP LEG 31
}

\author{
Arnold H. Bouma, Texas A\&M University, Department of Oceanography, College Station, Texas
}

\begin{abstract}
Sedimentary structures of 101 randomly selected samples from eight holes drilled during DSDP Leg 31 have been studied by visual observation and X-ray radiography. Although some scattering occurs, trends can be established between lithology and the sedimentary structures present.

Volcanic conglomerates and conglomeratic sandstones normally do not reveal sedimentary structures. However there is some indistinct and very indistinct medium and thin bedding in about one third of those samples. The sediments are considered to be debris flow deposits.

Volcanic ash (sand and pelitic sand) contains numerous sedimentary structures, such as regular and irregular medium and thin bedding and thick and thin lamination, foreset bedding, wedge-shapes and lenticularities, slumping, loadcasts, erosional contacts, and bioturbation.

Tuffs and sandstones appear to be homogeneous, while muddy sands and sandy muds can have as many sedimentary structures as the volcanic ashes. Silty clays reveal fewer sedimentary structures, while fine clays and red deep-sea clays contain only some vague thin lamination and evidence of burrowing activity. The shaly sediments from Hole 298 proved to be practically homogeneous.

Nannofossil oozes and chalks contain a variety of structures that increase in type and number with increase in clay or fine volcanic ash content.

Most sediments except the clays, tuffs, and sandstones show irregularity in deposition, and the sedimentary structures often indicate lateral secondary transport.
\end{abstract}

\section{INTRODUCTION}

During Leg 31 samples were collected from cores obtained in the Philippine Sea and the Sea of Japan for a study on sedimentary structures. All samples consisted of plan parallel slices, varying in thickness from 3-10 $\mathrm{mm}$, and cut in stratigraphical directions.

A total of 101 sample slices were studied (Table 1). Their selection was based primarily on availability of time, absence of coring distortion, and visual description, rather than on a systematic distribution. The locations of the holes from which samples were taken are given in Figure 1. The vertical distribution and lithologies of the slices is presented in Figure 2.

Three major groupings can be distinguished based on lithology-sedimentary structures. They are (1) the fine gravelly or gravel-bearing debris flow deposits with no sedimentary structures, or exhibiting some faint bedding; (2) various detrital lithologies that are not directly classified as debris flows, which contain a variety of structures; and (3) biogenic deposits (oozes) which have few sedimentary structures. Figure 2 as well as Table 1 presents a more detailed breakdown of lithologies in order to demonstrate the interrelationships more accurately.

\section{SAMPLE PREPARATION}

Once the core sections were cut lengthwise and the archive halves described, samples were selected. In those cases where the sediment was completely unconsolidated, a part of the working half of the core was cleaned with the electro-osmotic knife in order to obtain a smooth, clean surface (Chmelik, 1967; Bouma, 1969). The selected part was then removed from the liner by cutting the upper areas free, filling those cuts with water, placing a strip of plexiglas on that section and removing the part from the liner. This half core was then trimmed to obtain vertical sides about $9 \mathrm{~mm}$ high and enclosed by plexiglas strips on a plexiglas base. The slice was covered with a strip of wax paper to prevent later sticking of a covering plexiglas plate. The sample was taped, sealed in flat-lay plastic tubing with a wet foam fragment and stored in a refrigerated area.

In the laboratory the top plexiglas plate and the wax paper were removed and replaced by a very thin plexiglas plate that then served as bottom during radiography.

Samples from more consolidated and hard cores were cut with a bandsaw or a diamond saw. These sample slices were packed similar to the method described 
TABLE 1

Distribution of Sedimentary Structures According to Main Lithological Groupings

\begin{tabular}{|c|c|c|c|c|c|c|c|c|c|c|c|c|c|c|c|c|c|c|c|c|}
\hline $\begin{array}{c}\text { Main } \\
\text { Lithological } \\
\text { Group }\end{array}$ & $\begin{array}{c}\text { Sample } \\
\text { (Interval in cm) }\end{array}$ & 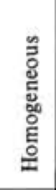 & 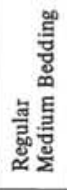 &  & 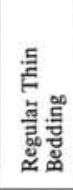 & 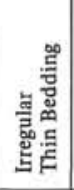 & 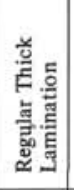 & 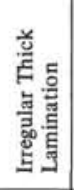 & 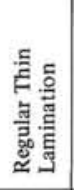 & 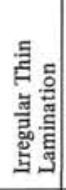 & 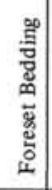 & $\begin{array}{l}\frac{a}{3} \\
\frac{2}{2} \\
3 \\
3\end{array}$ & 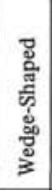 & 衰 & 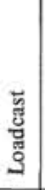 & 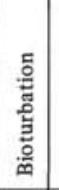 & 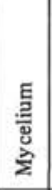 & 蹗 & 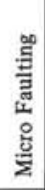 & 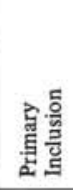 \\
\hline $\begin{array}{l}\text { Volcanic } \\
\text { conglomerate } \\
\text { and } \\
\text { conglomeratic } \\
\text { sandstone }\end{array}$ & 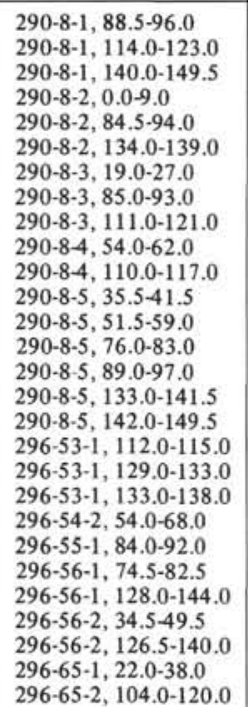 & $\begin{array}{l}+ \\
+ \\
+ \\
+ \\
+ \\
+ \\
+ \\
+ \\
+ \\
+ \\
+ \\
+ \\
+ \\
+ \\
+ \\
+ \\
+\end{array}$ & $\begin{array}{c}(()) \\
(()) \\
(()) \\
(()) \\
+ \\
(()) \\
(1) \\
\text { () }\end{array}$ & & $\begin{array}{l}\text { () } \\
\text { () }\end{array}$ & & & & & & & & . & & & & & & & \\
\hline $\begin{array}{l}\text { Volcanic ash } \\
\text { (sand and } \\
\text { pelitic sand- } \\
\text { stone) }\end{array}$ & 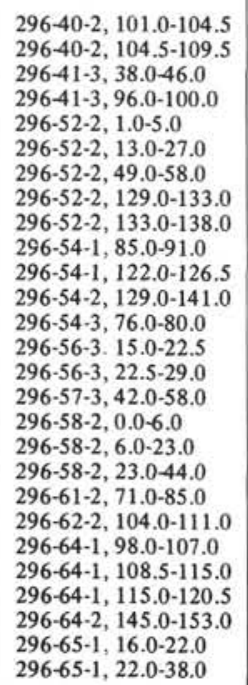 & $\begin{array}{l}() \\
+ \\
+\end{array}$ & $\begin{array}{c}+ \\
(()) \\
(()) \\
+\end{array}$ & () & $\begin{array}{l}\text { () } \\
\text { () } \\
\text { () } \\
\text { () } \\
\text { () }\end{array}$ & & $\begin{array}{l}+ \\
+ \\
+\end{array}$ & $\begin{array}{l}+ \\
+ \\
+ \\
+\end{array}$ & $\begin{array}{c}+ \\
\\
\text { () } \\
+ \\
+ \\
\text { () }\end{array}$ & $\begin{array}{l}+ \\
+ \\
\text { () } \\
+ \\
\text { () } \\
\text { () }\end{array}$ & + & () & + & () & () & $\begin{array}{l}\text { () } \\
+ \\
+ \\
+ \\
+ \\
+ \\
+\end{array}$ & & $\begin{array}{l}+ \\
+\end{array}$ & & \\
\hline
\end{tabular}


TABLE 1 - Continued

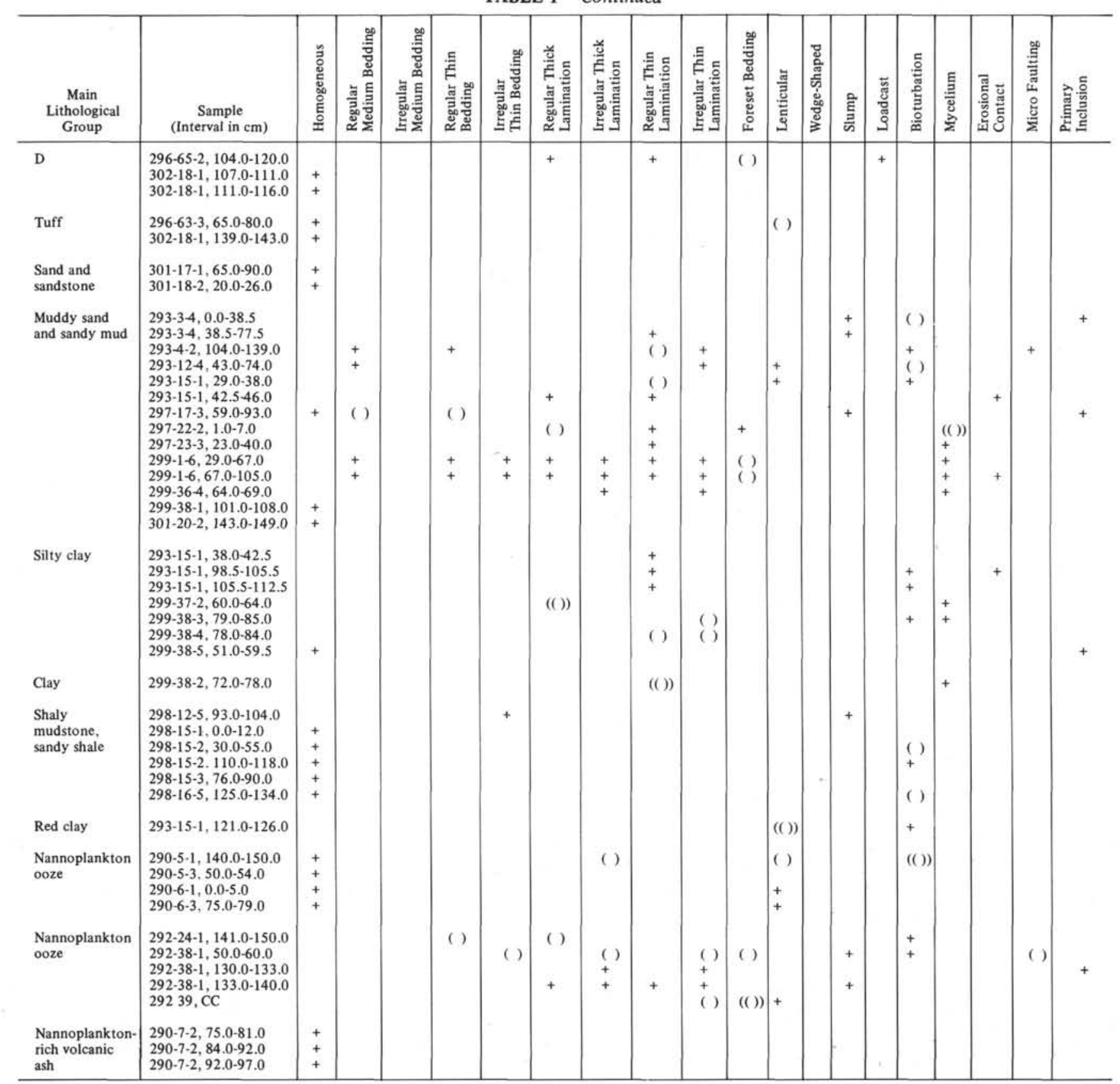




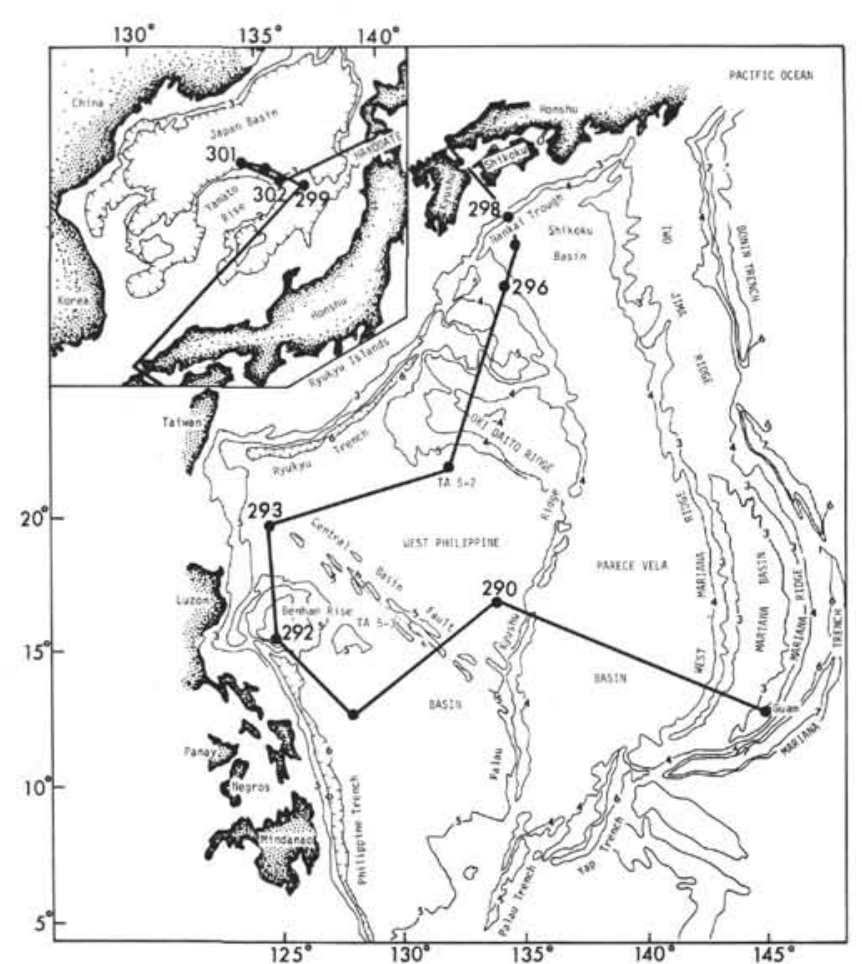

Figure 1. Simplified map of the Philippine Sea and the Sea of Japan with cruise track and stations. Samples were collected for this study from the numbered stations.

above. All sample slices were radiographed and the radiographs and samples described. A selected number of radiographs were contact printed, and the corresponding sample slices photographed and enlarged to original size. Kodak Industrial X-ray film type AA was used.

\section{OBSERVED SEDIMENTARY STRUCTURES}

Two main categories of sedimentary structures, slightly different from the classification given by Maurrasse (1973), have been distinguished in the samples. Each category can be subdivided as shown below, and illustrated in Figures 3-14.

\section{Primary Structures}

1. Bedding and lamination

a. Simple bedding and lamination, regular or irregular

b. Composite bedding and lamination

c. Foreset bedding

d. Homogeneous

2. Graded bedding

3. Wedge-shaped and lenticular

4. Primary inclusions or nests

5. Erosional contacts

\section{Secondary Structures}

1. Bioturbation

2. Penecontemporaneous deformation
a. Load casting
b. Slumping
c. Microfaulting

3. Mycelium

\section{Simple and Composite Bedding and Lamination}

Simple bedding and lamination indicating only minor variations within one major lithology (sufficient to reveal these structures), is quite common in the sediments cored (Figures 3B, 5B, 6, 7, 10, 13). Composite bedding refers to interlayered sediments, normally consisting of alternations of sand, sandy silt, sandy clay, clayey sand, clayey silt or clay, or of alternations between more or less similar lithologies with different colors (Figures 7B, 12). Foreset bedding has only been observed in sand-silt size material (Figures 6A, 8, 9).

Due to coring distortions and disruptions it is not possible to use the fine subdivisions published by Ingram (1954), and Campbell (1967). Laminae are defined here as very thin beds having thicknesses up to 3 $\mathrm{mm}$ (thin laminae; Figures $6 \mathrm{~A}, 6 \mathrm{~B}, 9$ ) or 3-6 mm (thick laminae; Figures 5B, 6A, 6B, 7B, 9, 10A). Thin bedding comprises thicknesses ranging from about $6 \mathrm{~mm}$ to 12 $15 \mathrm{~mm}$ (Figures 3B, 5B, 6B, 13), while medium bedding covers the thickness range from $12-15 \mathrm{~mm}$ to $30 \mathrm{~mm}$ (Figures 3B, 6A, 7B, 12). When laminae and bed contacts are more or less straight and parallel, the structure is called regular. In all other cases the term irregular is used. However this term may not always indicate that the formational cause is natural. In some instances it becomes impossible to ascertain whether the origin is natural or artificial, especially when dealing with soft sediments (Figure 7A).

Foreset bedding has not been observed frequently. Reference to like nature is considered to be sufficient to describe the few examples instead of presenting a full classification of which only a few members were encountered during Leg 31 .

\section{Homogeneous Bedding}

Homogeneous or massive bedding is used where observations, visual and/or radiographic, fail to distinguish any primary sedimentary structures (Figures $3 \mathrm{~A}, 4 \mathrm{~A}, 5 \mathrm{~A}, 9,11,14$ ) (see also Reineck and Singh, 1973).

\section{Graded Bedding}

In many cores a poorly developed graded bedding could be seen. It normally occurs in sediment that has a scattered matrix throughout, displaying a decrease of the average larger grain size in upward direction (Figures 7B, 8B, 12). This observation becomes distorted when rock fragments and/or larger single grains are present, revealing a range in original specific densities, and thus in hydrodynamic size/weight ratios.

\section{Wedge-Shaped and Lenticular}

Occasionally the laminae or thin beds terminate at one side (wedge-shaped) or at two sides (lenticular) of a core (Figures 6B, 7A, 8B, 13A, 13B). Wedge-shaped beds may represent only one side of a cored lenticular structure. It is not always possible to indicate if such endings are natural in origin or due to coring. Some of the smaller lenticular shapes may also be cross sections of burrows. In most cases those can be identified as due to internal characteristics, width/height ratio, and the general presence or absence of bioturbation through the 


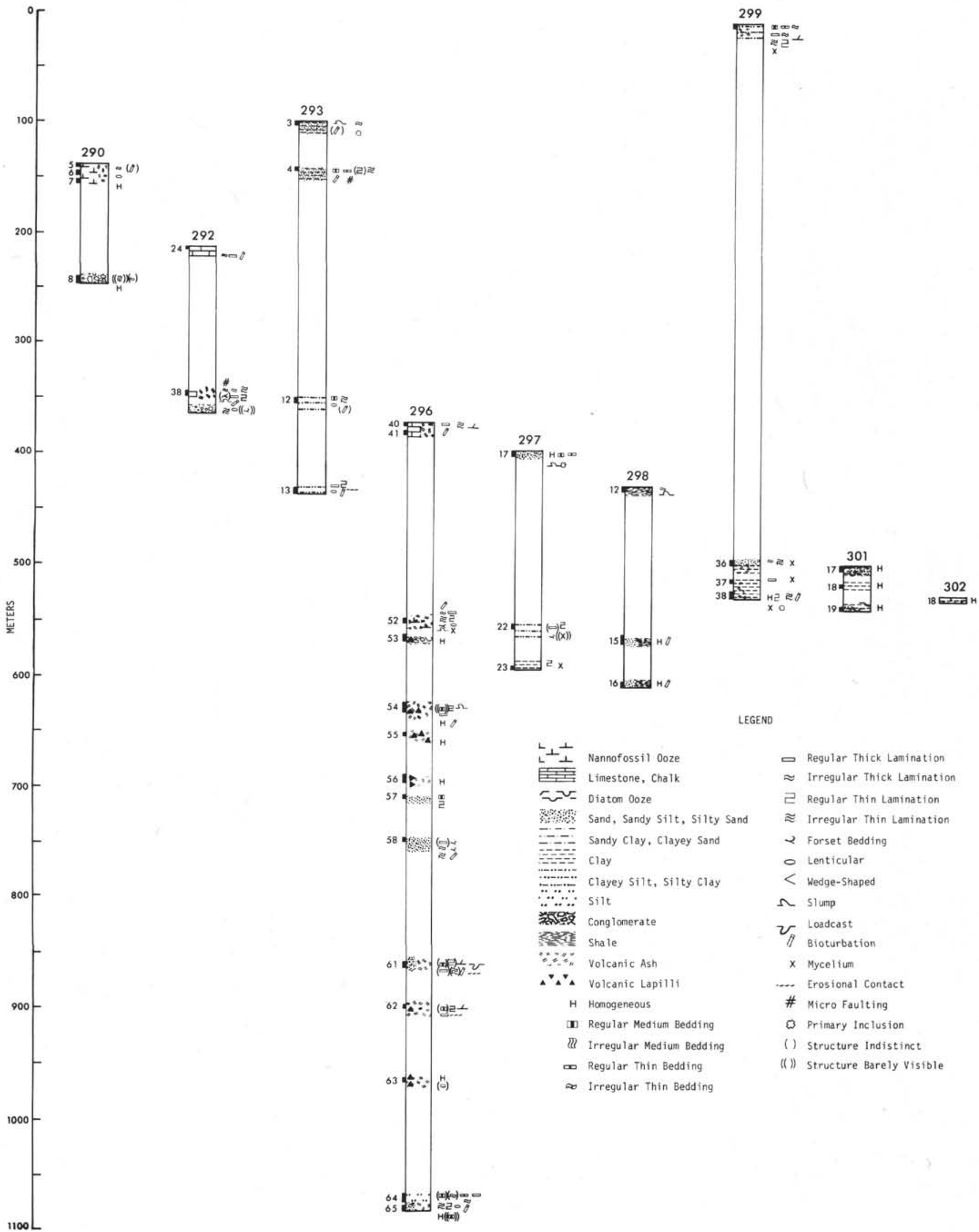

Figure 2. Graphic display of the distribution of the sample slices used in this study. 


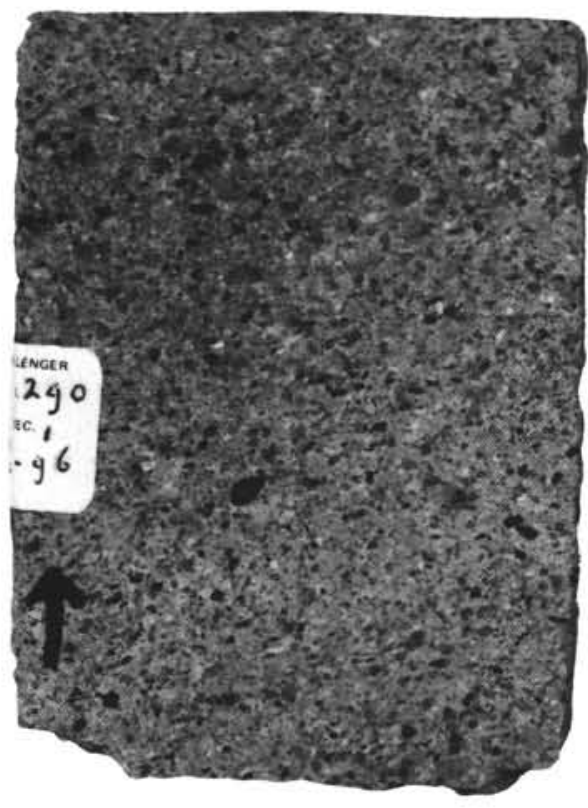

A
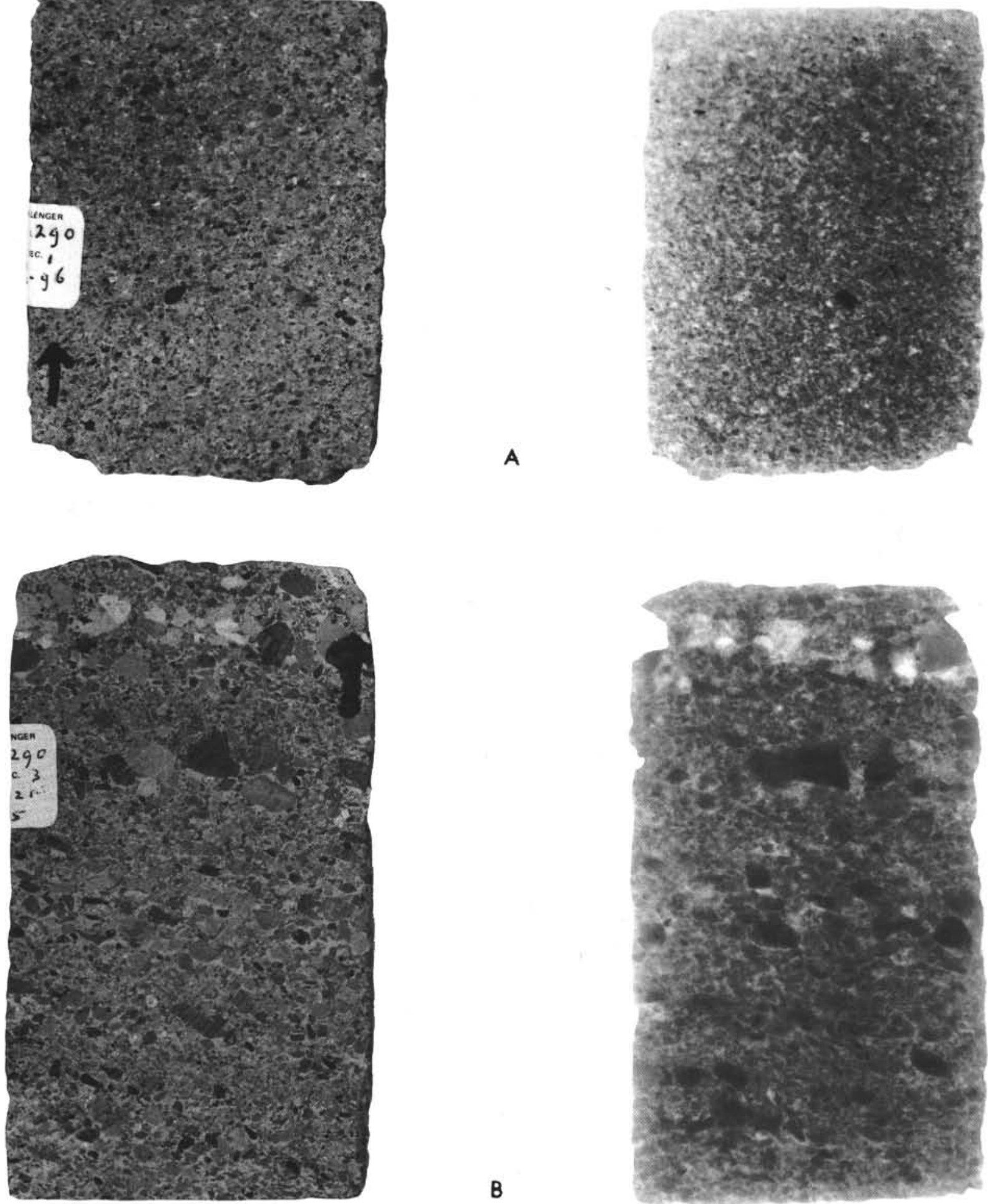

Figure 3. Photographs (left) and radiographs (right) of slices of Samples (A) 290-8-1, 88.5-96.0 cm, homogeneous, and (B) 290-8-3, 111-121 cm, indistinct thin bedding. Debris flow deposits. 


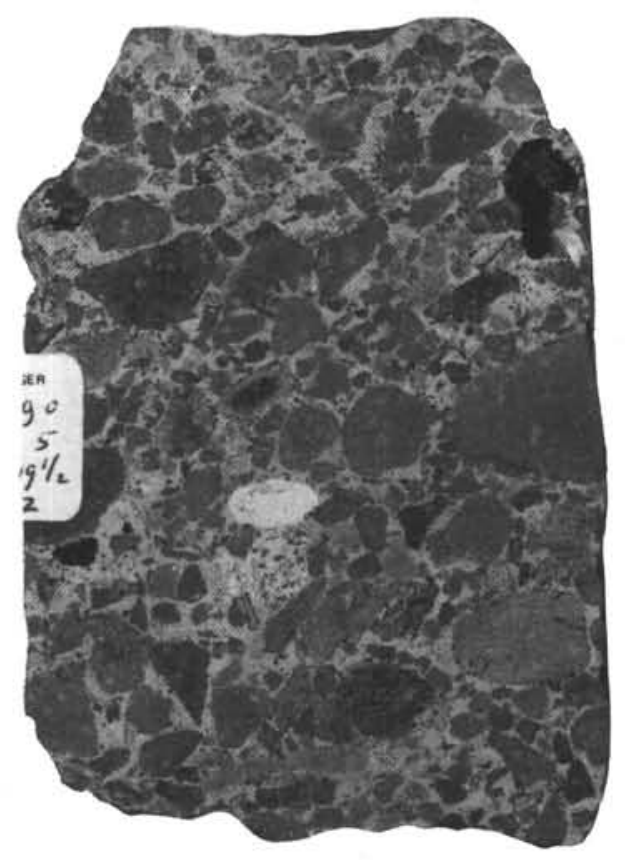

A
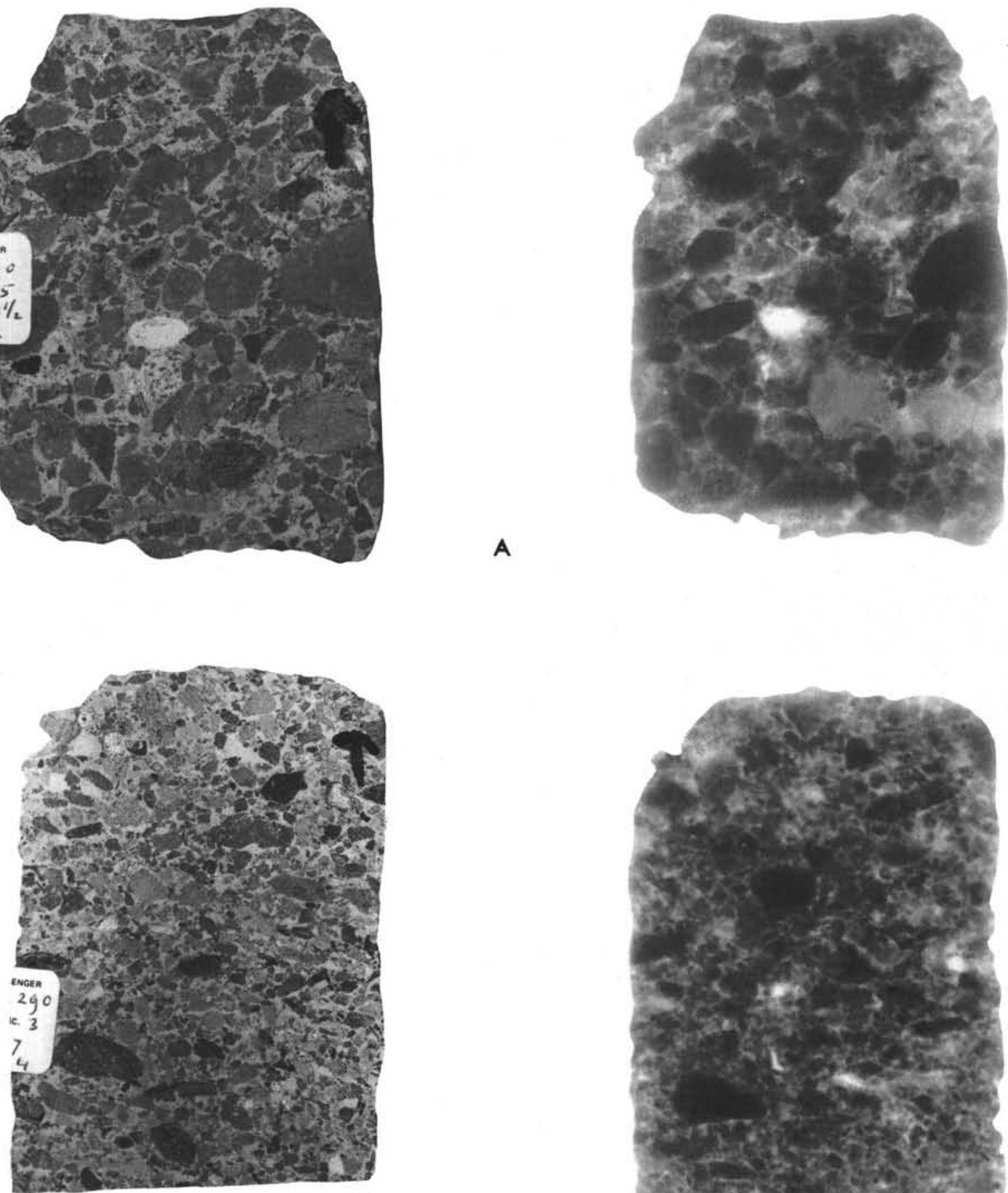

B

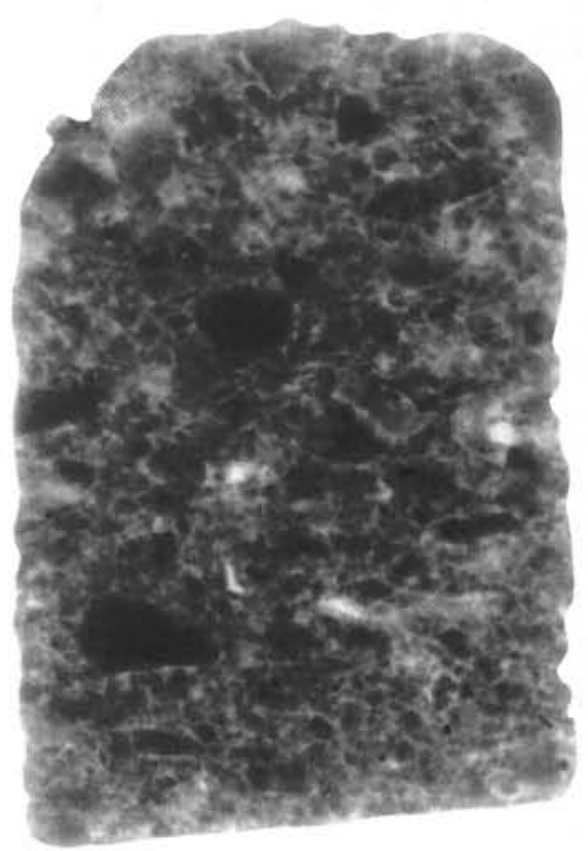

Figure 4. Photographs (left) and radiographs (right) of slices of Samples (A) 290-8-5, 142-149.5 cm, homogeneous; and (B) 290-8-3, 19-27 cm, either homogeneous or contains a possible faint medium bedding. Debris flow deposits. 

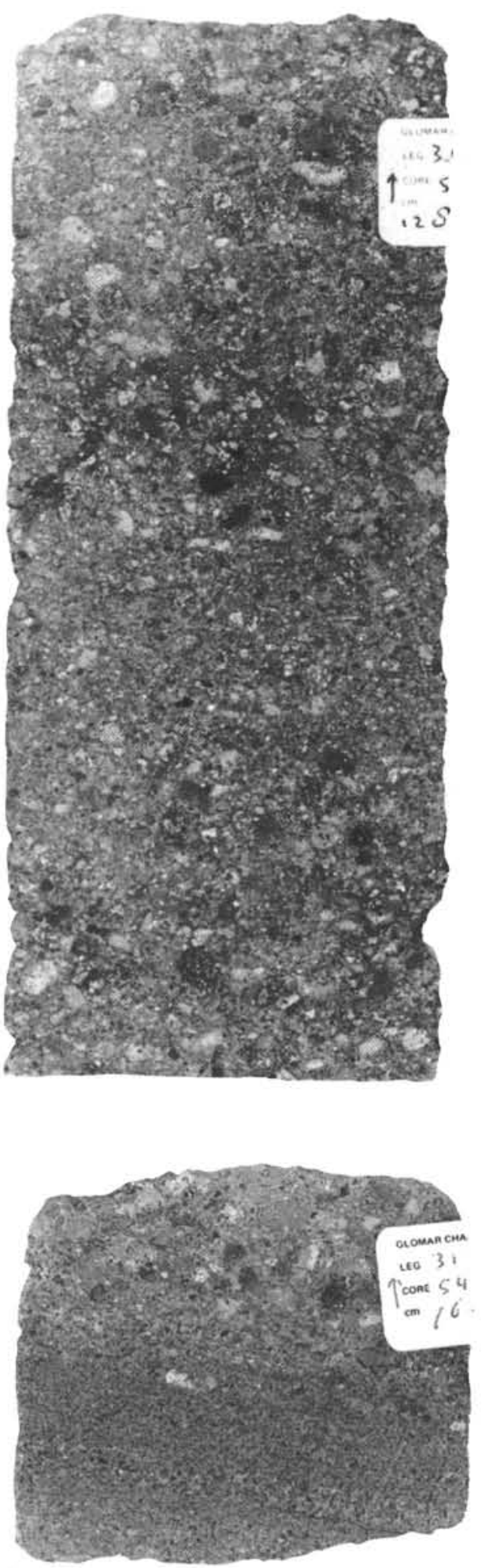

A
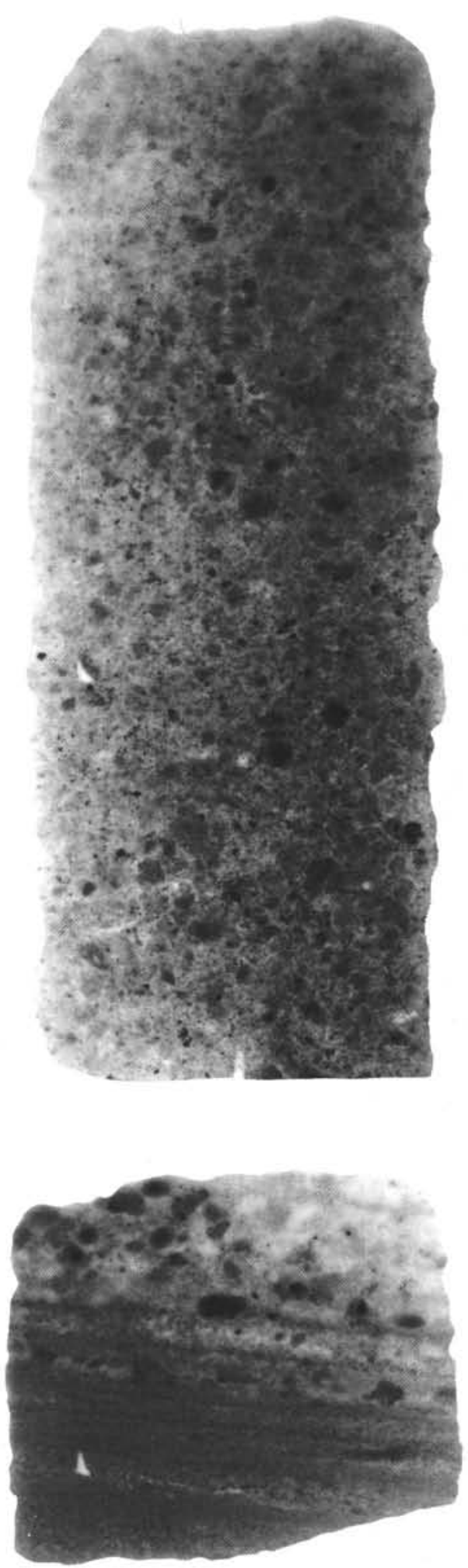

Figure 5. Photographs (left) and radiographs (right) of slices of Samples (A) 296-56-1, 128-141.5 cm, homogeneous (petrology varies from those in Figures 3 and 4); and (B) 296-54-3, 76-80 cm, homogeneous in its upper part, displaying thick lamination in the lower two-thirds. Both are interpreted as debris flow deposits. 


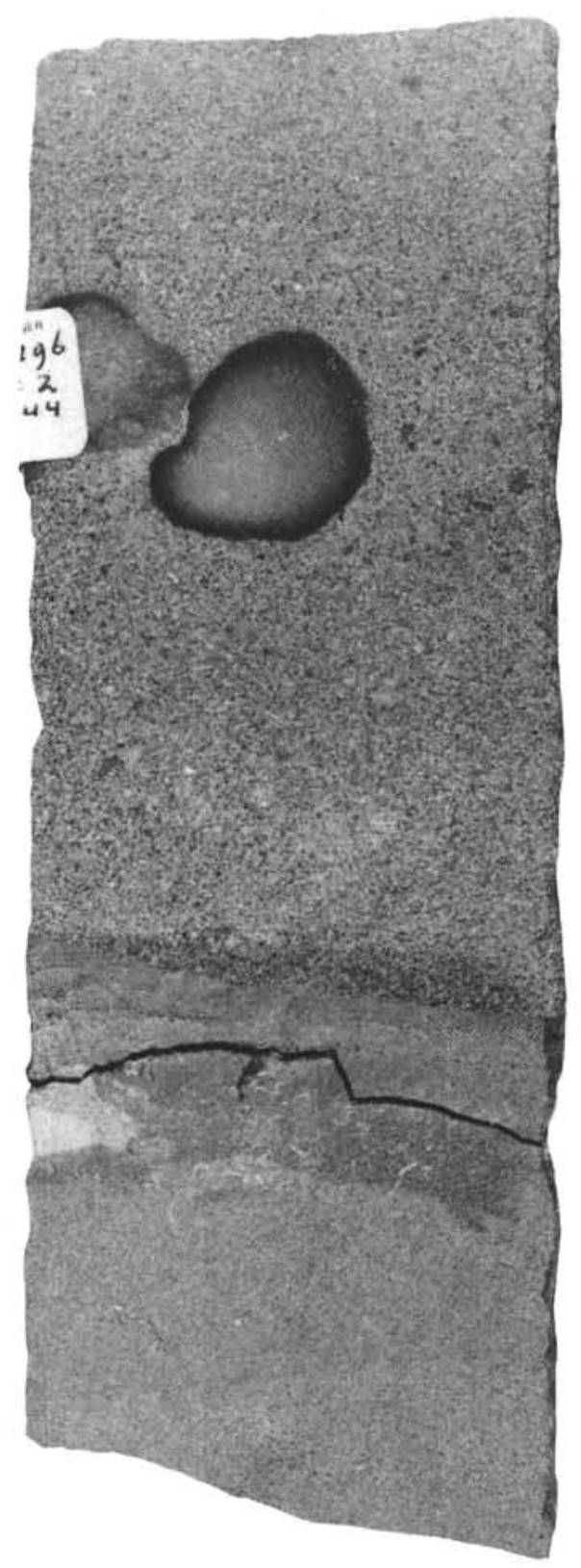

A
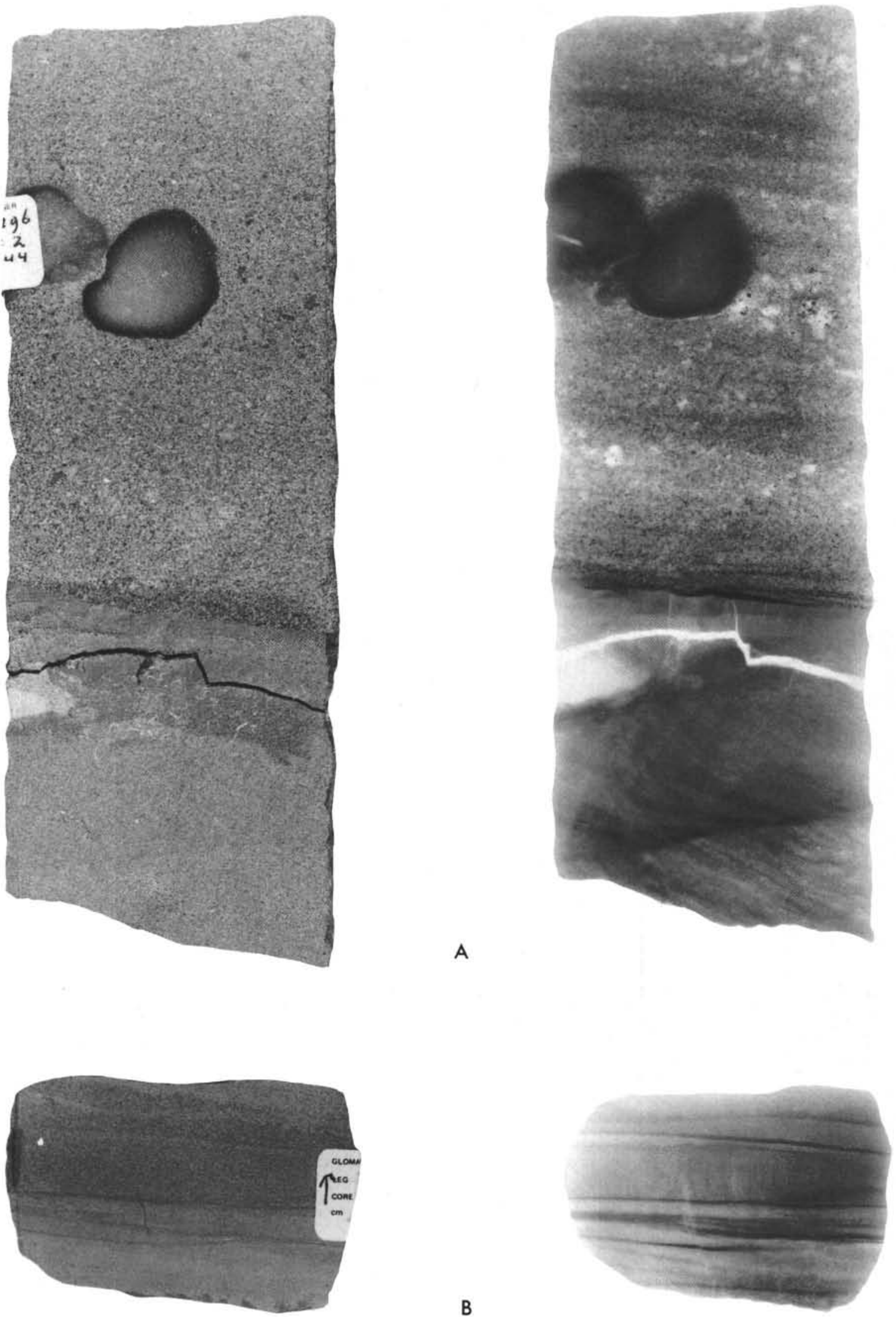

Figure 6. Photographs (left) and radiographs (right) of slices of (A) Sample 296-58-2, 23-44 cm, thin bedding and thick lamination in the upper half, and two volcanic bombs; lower portion contains sets of foreset bedding: (B) Sample 296-52-2, 129-133 cm, thick and thin lamination and possibly some foreset bedding. Both represent volcanic ashes that were partly redeposited. 


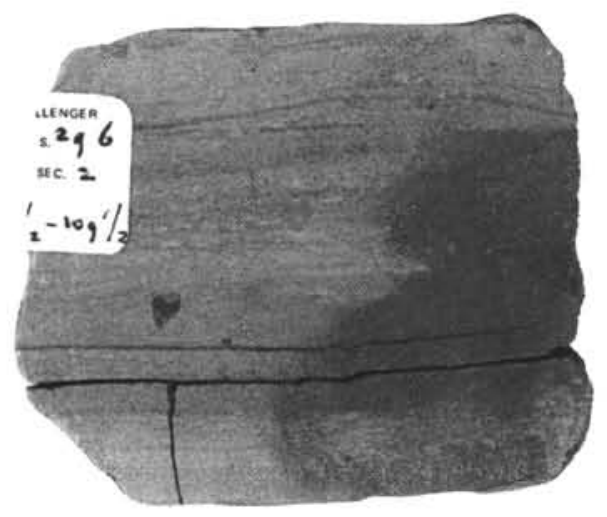

A
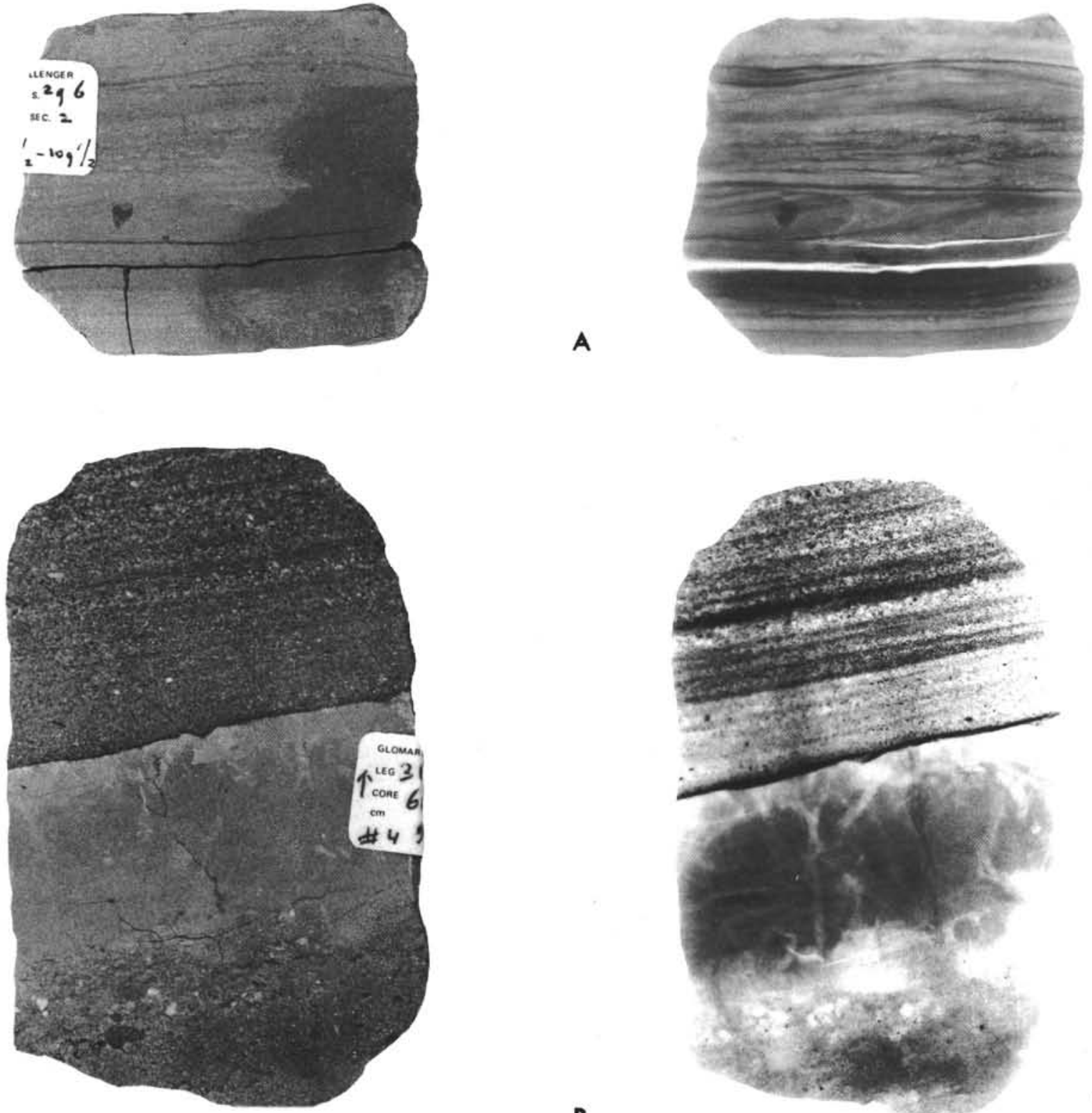

B

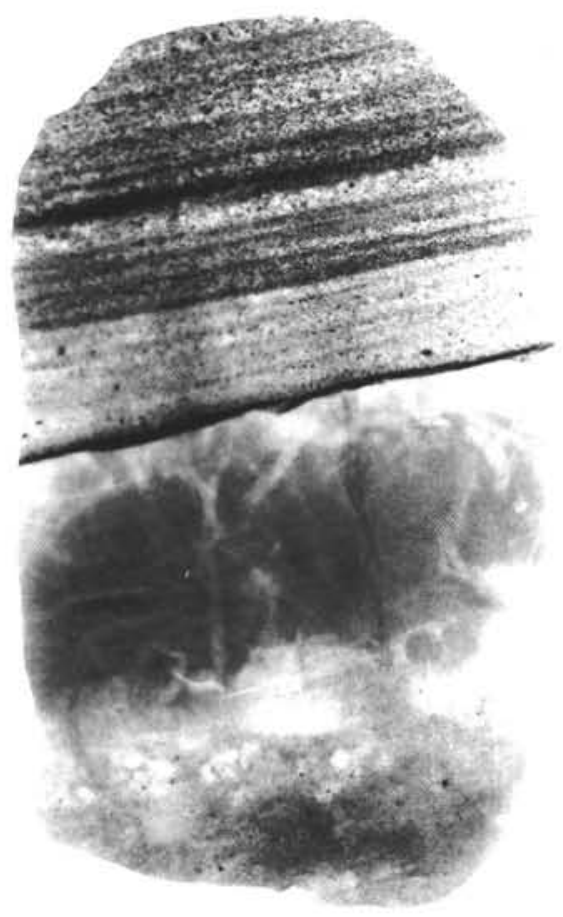

Figure 7. Photographs (left) and radiographs (right) of slices of Samples (A) 296-40-2, 104.5-109.5 cm, regular and irregular thin lamination with some foreset bedding and possible burrows: (B) 296-64-1, 98-107 cm the upper part contains thick and thin parallel lamination, while the lower part shows graded bedding, above which faint irregular thick laminae occur, followed by intensive burrowing. Both samples are volcanic ashes which underwent bottom traction. 

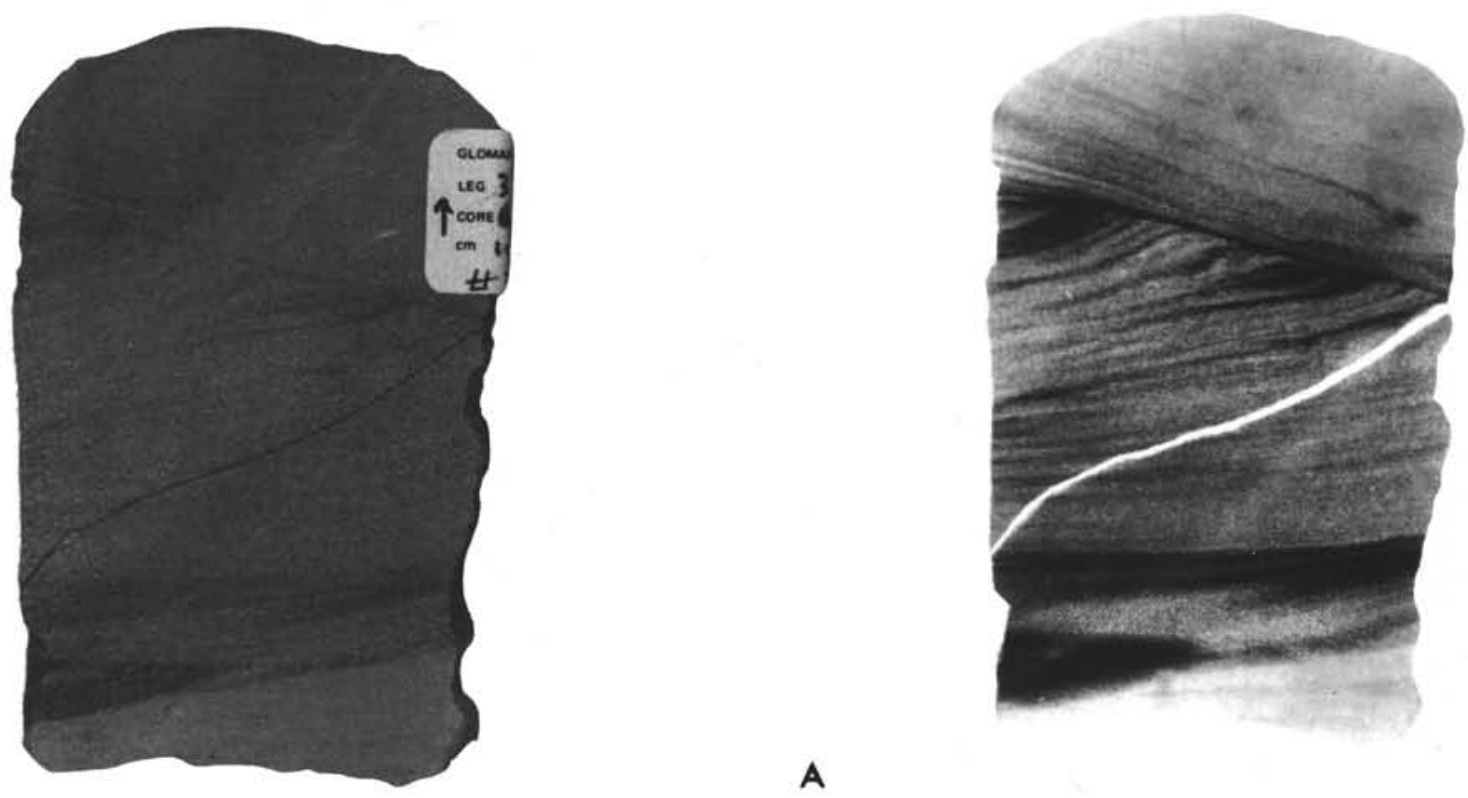

A
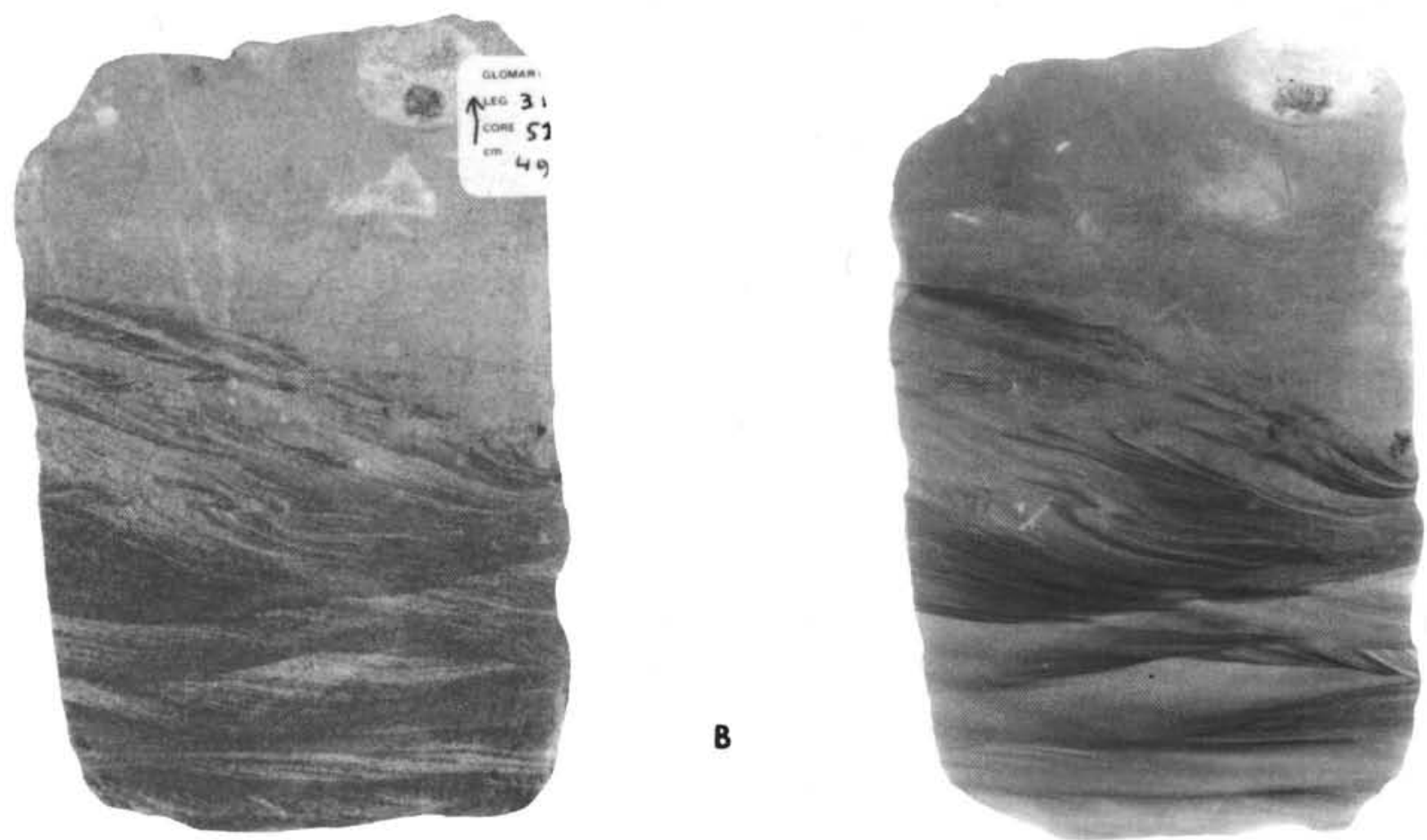

Figure 8. Photographs (left) and radiographs (right) of slices of Samples (A) 296-62-2, 104-111 cm, thin bedding, thick and thin lamination, foreset bedding, and an erosional contact: (B) 296-52-2, 49-58 cm, regular and irregular thin and thick lamination, foreset bedding with some lenticularity, disrupted by slumping in the middle part. Both samples are volcanic ashes that underwent bottom transport. 

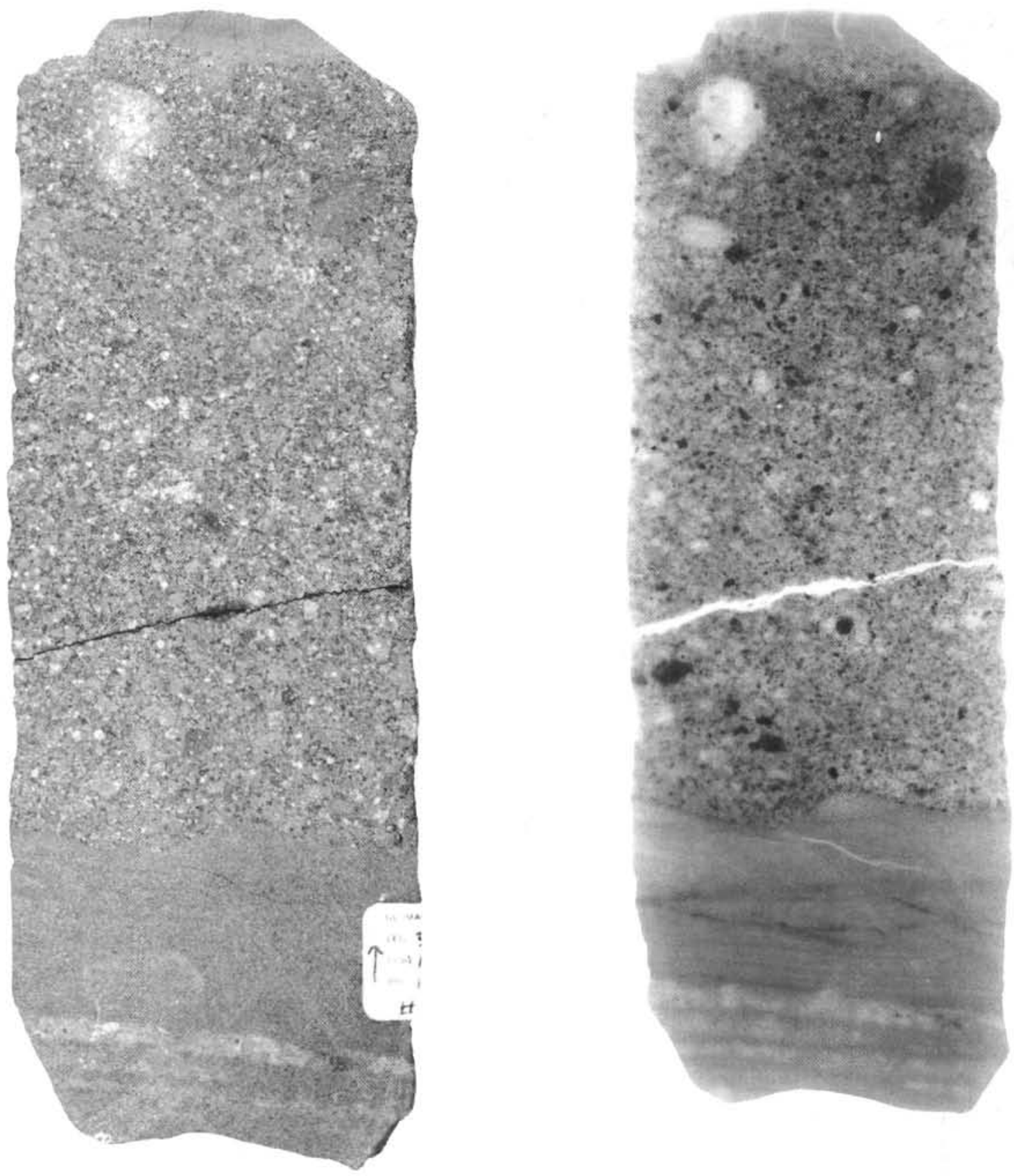

Figure 9. Photograph (left) and radiograph (right) of slice of Sample 296-65-2, 104-120 cm. The upper two-thirds is homogeneous, and is interpreted as a debris flow deposit. The lower third contains thick and thin parallel lamination and faint foreset bedding. This is a volcanic ash that at least partly underwent bottom transport. On the contact of both lithologies a load cast or a fill of a ripple surface can be observed. 


\section{SEDIMENTARY STRUCTURES OF PHILIPPINE SEA AND SEA OF JAPAN SEDIMENTS}
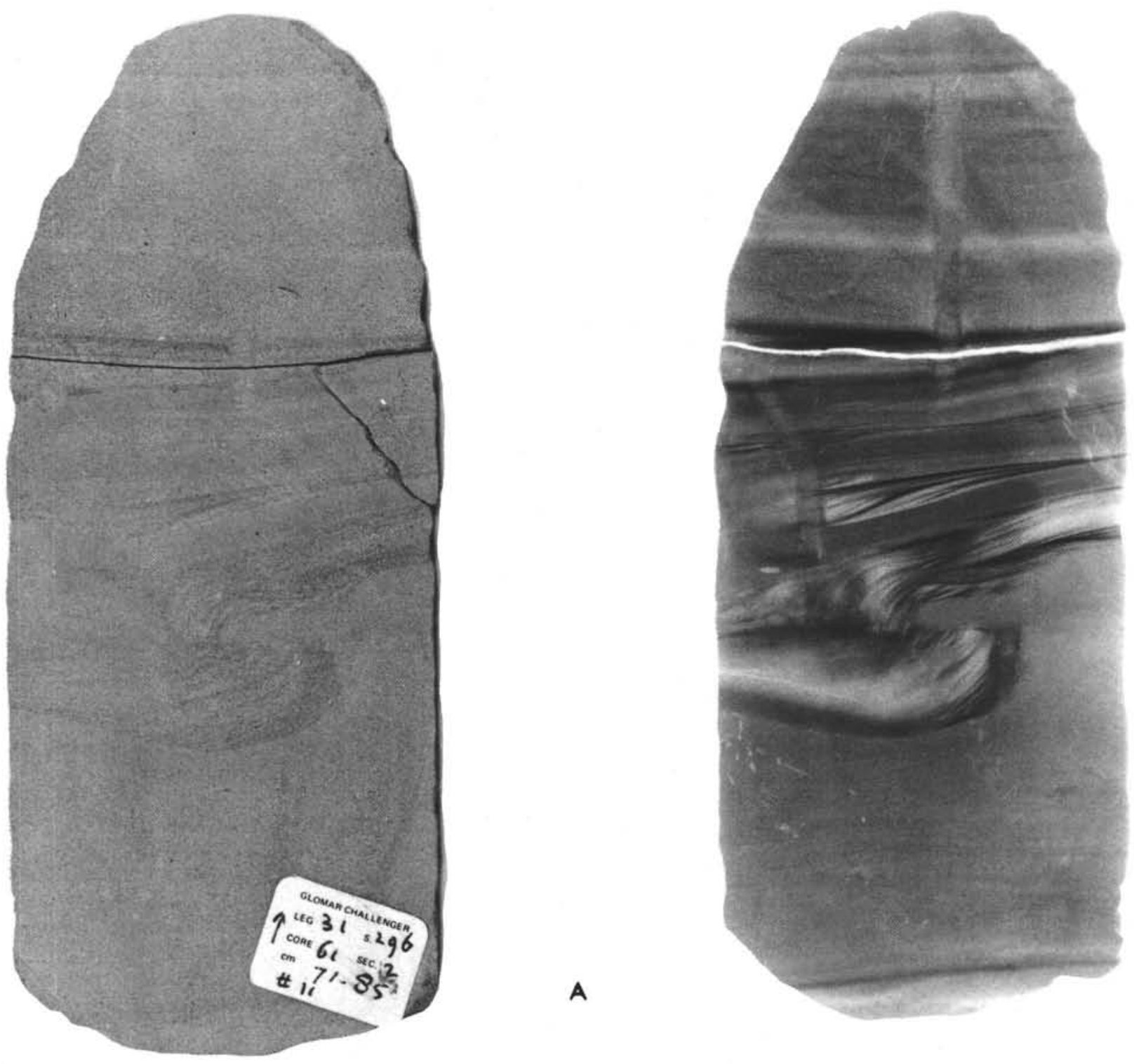

A
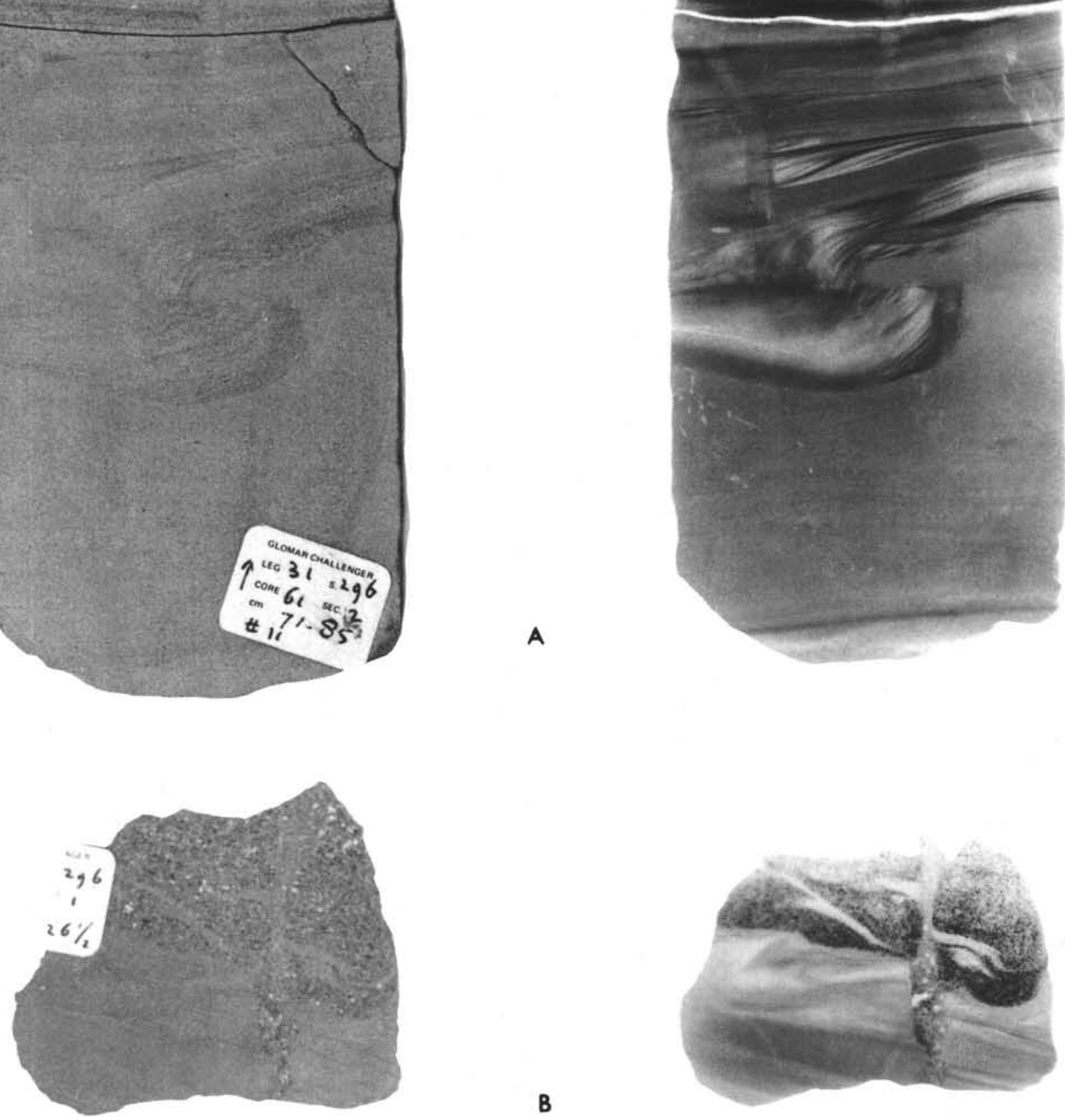

Figure 10. Photographs (left) and radiographs (right) of slices of (A) Sample 296-61-2, 71-85 cm, volcanic ash with thin bedding, thick lamination, regular and irregular thin lamination, possible foreset bedding, burrows and a possible load cast that underwent a horizontal translation. (B) Sample 296-54-1, 122-126.5 cm, coarser volcanic ash on top of finer ash. Thin and thick lamination (regular and irregular) with possible foreset bedding. Slumping is considered the cause of the deformations that make interpretations difficult. The coarser vertical stem is interpreted as a burrow rather than a clastic dike. 



Figure 11. Photograph (left) and radiograph (right) of slice of Sample 296-63-3, 65-80 cm. This volcaniclastic tuff is homogeneous with possible faint lenticularities.

sediment in other directions (Maurrasse, 1973; Reineck and Singh, 1973).

\section{Primary Inclusions}

Primary inclusions, nests, or pockets are concentrations of several foreign fragments such as foraminifera, shell and plant fragments, or coarser particles (Figures 6, 12,14?). The origin of such inclusions is synsedimentary and not diagenetic. In some cases the concentration may be the result of animal activity.

\section{Erosional Contacts}

Only when angular contacts that indicate erosion can be detected, as being different from the sedimentation/erosion cycles natural to the forming of most primary sedimentary structures, can the term erosional contact be used (Figures 6A, 8A, 9). In some instances it may be impossible to determine if the contacts are natural or artificial. Such a contact is present in Sample $299-1-6,80 \mathrm{~cm}$, and may be due to a minor jumping of the core bit (see Bouma, this volume).

\section{Bioturbation}

This denotes the structures produced by the activity of living animals along the sediment surface and/or within the sediment (Figures 7A, 7B, 10A, 10B, 13A?). A number of distinct examples from DSDP cores from the Caribbean are given by Maurrasse (1973), while the various classifications, made by several investigators, are summarized by Reineck and Singh (1973), and Warme et al. (1973).

Bioturbation structures not only cut through sedimentary structures, but their density may be so high that no recognizable primary structures remain. When bioturbation is so intense that formed burrows are destroyed, the term mottling or mottled bedding is applied.

\section{Load Casts}

When denser and normally coarser material sinks into underlying sediment, the term load cast is applied. This type of sole marking varies considerably in size and shape, and consequently is seldom recognizable in the 

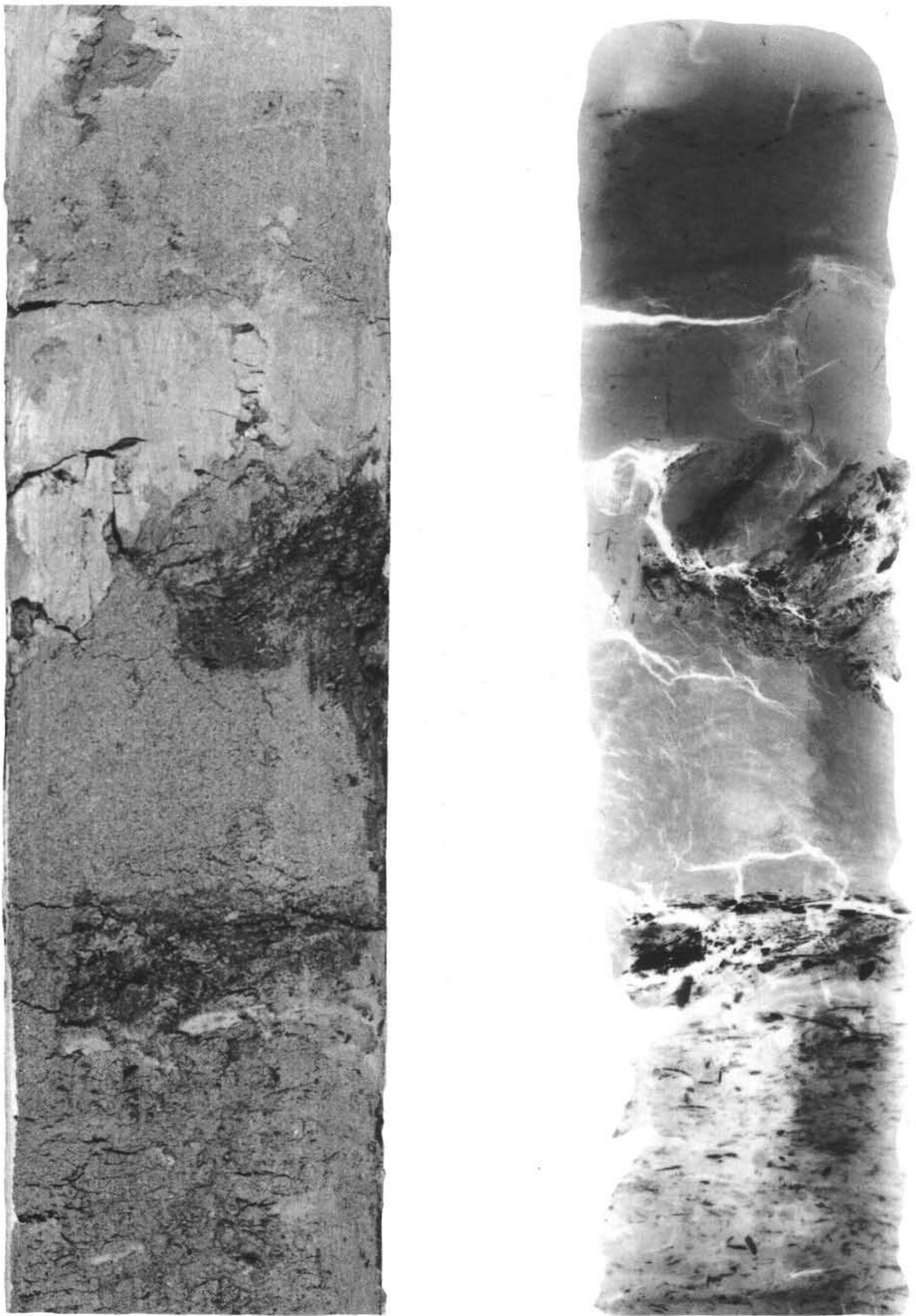

Figure 12. Photograph (left) and radiograph (right) of slice of Sample 297-17-3, $59-93 \mathrm{~cm}$. Muddy sand and sandy mud alternations with homogeneous parts, medium and thin bedding, slump (just above the middle) and primary inclusions of plant fragments. Such deposit is often considered a turbidite, although it does not display real turbidite characteristics, except for some graded bedding in the upper sand. 


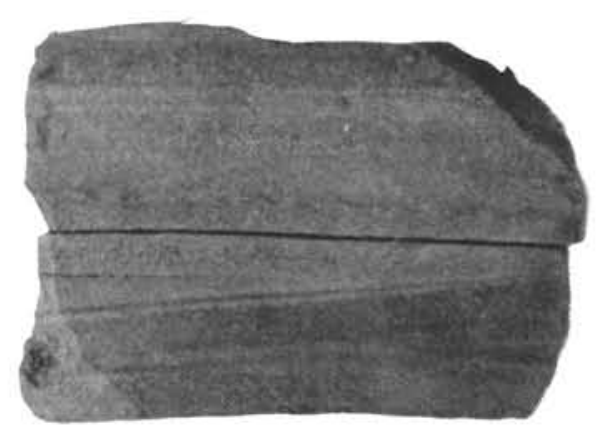

\section{A}
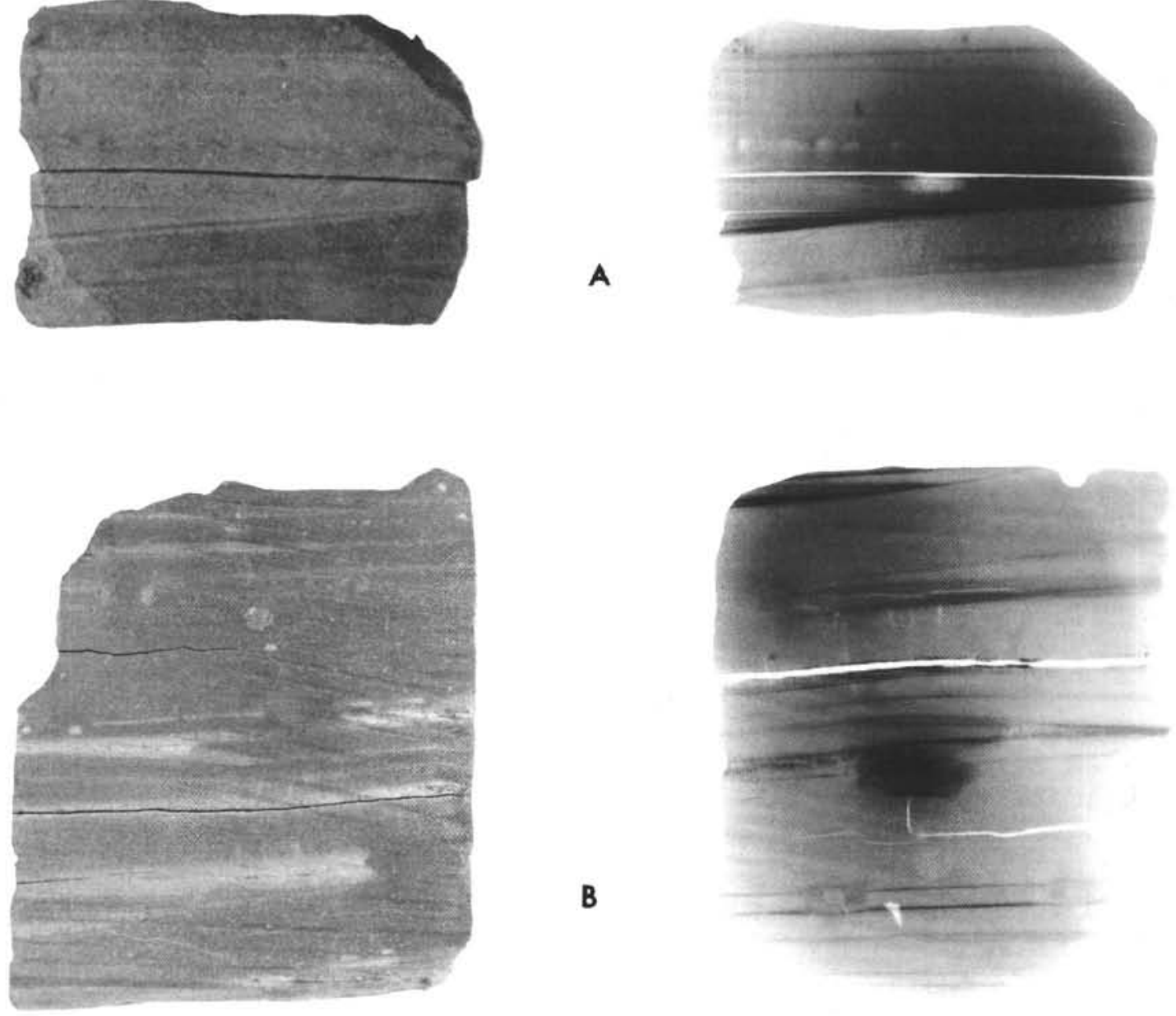

Figure 13. Photographs (left) and radiographs (right) of slices of Samples (A) 293-15-1, 42.5$46.0 \mathrm{~cm}$, a muddy sand with thick and thin parallel lamination and an erosional contact (?) (low angle): (B) 293-15-1, 98.5-105.5 cm, a silty clay with thin and thick laminae, faint lenticularities, and wedge-shapes and possible burrows and erosional contact.

restricted diameter of a core. It is also impossible to normally identify load casts from flute casts or from cross sections of groove casts, especially when only one vertical section is available. Potter and Pettijohn (1963), Dzulynski and Walton (1965), and Reineck and Singh (1973) present several examples and literature references (see also Bouma and Brouwer, 1964).

\section{Slumping}

This term indicates all penecontemporaneous deformation structures that result from movement or displacement of already deposited material, mainly under the influence of gravity but with a slope component included (Bouma, 1968, 1972). The variation in size, shape, and degree of internal deformation is extremely large (Potter and Pettijohn, 1963; Dzulynski and Walton, 1965) (Figures 8A?, 8B, 12). In many cases, when dealing with soft unconsolidated sediments, it is impossible to indicate if the slump is natural, or artifically induced by the coring action.

\section{Microfaulting}

The origin may be artificial, however when regular structures occur above and below a microfault, and when the fault is sharp, the investigator almost certainly is dealing with a naturally formed feature. Microfaults may result from a slumping action or differential consolidation (Bouma, 1968, 1972). Only a limited number were observed in the Leg 31 cores presumably because of the intense coring distortion which hinders accurate observations.

\section{Mycelium}

Bouma (1968) introduced this term into the field of unconsolidated sediments to describe thin, light-colored strings that vary in length from less than $1 \mathrm{~cm}$ to several centimeters (see also Reineck and Singh, 1973). They are only observable on radiographs. The strings may be straight or slightly curved, and often reveal sharp bends. Their diameter is oval to round in cross section, and normally less than $0.5 \mathrm{~mm}$. Their origin is difficult to 

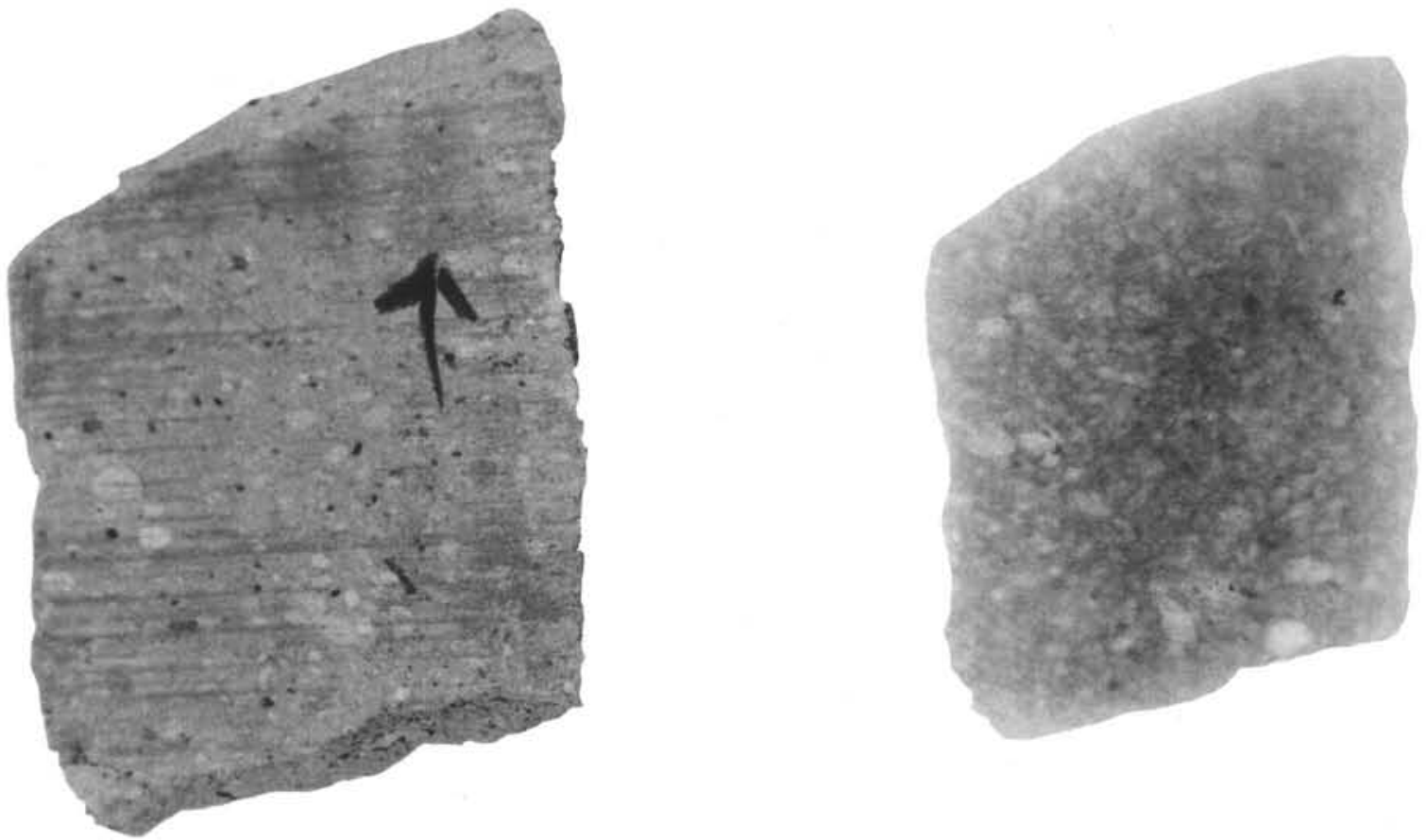

Figure 14. Photograph (left) and radiograph (right) of slice of Sample 290-7-2, 75-81 cm. This nannoplankton-rich volcanic ash is completely homogeneous and displays no sedimentary structures. The larger light-colored parts are larger fragments.

determine, but since they are light colored on radiographs, which means a higher density than the surrounding fine-grained and normally rather homogeneous mud, it is assumed that they represent a carbonate filling of little cracks and small burrows.

\section{DISTRIBUTION OF SEDIMENTARY STRUCTURES - CONCLUSIONS}

The uneven, unsystematic sampling prevents the development of a real distribution of sedimentary structures over the various lithologies (Figure 2). As a result only a limited interpretation can be given about the transport-sedimentation characteristics of the sediments cored during Leg 31 . However, Table 1 reveals that certain lithologic groups contain more sedimentary structures than other groups. Most limited in type of structures exhibited are the volcanic conglomerates and conglomeratic sandstones, the volcanic tuffs, the sandstones, the rather fine clays, and the nannoplanktonrich volcanic ashes.

The volcanic conglomerates and conglomeratic sandstones (Figures 3, 4, 5, 9 top) are normally homogeneous, or may show faint bedding. When dealing with larger sections than the samples used here, one can also observe some graded bedding over 0.5-3-meter sections. The larger grains seldom touch each other since they are imbedded in a matrix of fine material. These deposits are interpreted as debris flows, the result of a transport mechanism in which the larger grains are supported by a matrix consisting of a mixture of fine material and water (Middleton and Hampton, 1973). It is assumed that volcaniclastic deposits are set into motion because of instability which results from fast deposition, likely forming a slump which changes into a debris flow.
The tuffs (Figure 11) may be similarly interpreted, although it is very likely that little or less displacement occurred. They are probably the direct result of deposition of ejected volcaniclastic sediment particles of various sizes, some of which were ejected subaerially and became pumiced. These particles partly melted together, while a little fine material became incorporated during the depositional cycle.

Only two examples of sandstones were studied (both lacking sedimentary structures), too few to draw conclusions. Very fine-grained sediment like the normal clay reveals that most deep-sea detrital clay contains a very faint thin or thick lamination and often mycelium, the result of a pelagic rain and the normal fluctuations caused by stagnation on density interfaces, slow turbulence during "horizontal" motion through the water, or pulsations in the original input. The mycelium is considered to be a secondary formation. Red deep-sea clays are more homogeneous than detrital clays, but often reveal faint lenticularity due to bioturbation. Intense bioturbation is not uncommon in such deposits, although little was encountered in the Leg 31 cores.

The nannofossil-rich volcanic ashes are very finegrained, and reveal a large number of more or less round, lighter colored particles as well as darker colored ones under visual examination (Figure 14). At first glance they might be considered burrows, but it is apparent that they are generally spherical to oval. The lighter ones normally have a higher nannofossil content and it is likely that they were very light hydraulically but coherent enough (although soft), to have comparable or not much higher sinking rates than the finer ash, since they are not concentrated or display higher impact on the bottom. The reason for their roundness is uncertain, 
but may be a result from erosional processes. It is assumed that these sediments are generally deposited as pelagics, and that the inclusions arrived from shallower areas.

The nannofossil oozes and chalks contain a limited number of sedimentary structures. The reason the chalks have so many more bedding-lamination structures must be due to consolidation, making very faint to undiscernible structures more visible (Bouma, 1973). The bedding structures are considered to be the results of pulsations in the pelagic supply, which may be seasonal.

The sand-silt-clay combinations, volcaniclastic or not in origin, display an interesting amount of sedimentary structures (Table 1). The coarser they are, the more medium and thin bedding is present, although thin and thick laminae are the most obvious structures in this lithologic suite. The fine parts often contain mycelium. As an overall conclusion, practically all these sediment types have been redeposited by local bottom currents either as a result of particle by particle bedload transport, are concentrated by winnowing effects, or have been moved by bottom density currents.

The foreset bedding in Figure $6 \mathrm{~A}$ displays a minor climbing effect indicating a large sediment supply. This planar cross bedding is a unidirectional-current ripple type which contains minor internal deformation due to initial consolidation. The bottom current presumably was created by the vast dumping of volcaniclastic material resulting in temporarily local water motions (currents) that consequently moved material. In Figure $8 \mathrm{~A}$ a generally similar condition is presented. Figures $8 \mathrm{~B}$ and 9 show the result of much smaller currents in finer material. Although the origin of the water motion can be similar, it was more likely further away from the volcaniclastic dumping site. Deformation is rather well developed, indicating either instability on slope and/or fast sedimentation.

Lateral motion is revealed very well in Figure 10A where the material above some type of load cast moved to the left relative to the load cast, thereby deheading the cast. The deformation in Figure 12 can be partly the result of coring, although natural slumping can give similar pictures.

\section{ACKNOWLEDGMENTS}

The author thanks the Deep Sea Drilling Project for the opportunity to participate in the Glomar Challenger Leg 31 . He is very grateful to the members of the scientific and technical teams for their cooperation, specifically Stan White and Casey Moore who helped in collecting the samples.

My sons, Mark and Nils Bouma, spent most of their holidays in helping to carry out all the radiographic and photographic work, and Margie Dupler did all the typing. I am very thankful for their assistance.

\section{REFERENCES}

Bouma, A.H., 1968. Distribution of minor structures in Gulf of Mexico sediments: Gulf Coast Assoc. Geol. Soc. Trans., v. 18, p. $26-33$.

1969. Methods in the study of sedimentary structures: New York (John Wiley \& Sons), 458 p.

1972. Recent and ancient turbidites and contourites: Gulf Coast Assoc. Geol. Soc. Trans., v. 22, p. 205-221.

1973. Leveed-channel deposits, turbidites, and contourites in deeper part of Gulf of Mexico: Gulf Coast Assoc. Geol. Soc. Trans., v. 23, p. 368-376.

Bouma, A.H. and Brouwer, A. (Eds.), 1964. Turbidites: Amsterdam (Elsevier Publishing Co.), 264 p.

Campbell, C.V., 1967. Laminae, laminaset, bed and bedset: Sedimentology, v. 8, p. 7-26.

Chmelik, F.B., 1967. Electro-osmotic core cutting: Marine Geol., v. 5, p. 321-325.

Dzulynski, S. and Walton, E.K., 1965. Sedimentary features of flysch and greywackes. Developments in sedimentology, vol. 7: Amsterdam (Elsevier Publishing Co.), 274 p.

Ingram, R.L., 1954. Terminology for the thickness of stratification and parting units in sedimentary rocks: Geol. Soc. Am. Bull., v. 65, p. 937-938.

Maurrasse, F., 1973. Sedimentary structures of Caribbean Leg 15 sediments. In Edgar, N.T., Saunders, J.B., et al., Initial Reports of the Deep Sea Drilling Project, Volume 15: Washington (U.S. Government Printing Office), p. 833-845.

Middleton, G.V. and Hampton, M.A., 1973. Sediment gravity flows: mechanics of flow and deposition. In Middleton, G.V. and Bouma, A.H. (Eds.), Turbidites and deep-water sedimentation: Short course notes, SEPM Pacific Section, Anaheim, May 12, 1973, p. 1-38.

Potter, P.E. and Pettijohn, F.J., 1963. Palaeocurrents and basin analysis: Berlin (Springer-Verlag), 296 p.

Reineck, H.E. and Singh, I.B., 1973. Depositional sedimentary environments: Berlin (Springer-Verlag), $439 \mathrm{p}$.

Warme, J.E., Kennedy, W.J., and Schneidermann, N., 1973. Biogenic sedimentary structures (trace fossils) in Leg 15 cores. In Edgar, N.T., Saunders, J.B., et al., Initial Reports of the Deep Sea Drilling Project, Volume 15: Washington (U.S. Government Printing Office), p. 813-819. 